\title{
PERÍODOS DE MATOCOMPETIÇÃO NA CULTURA DA SOJA (Glycine max (L.) Merril),CULTI VARES SANTA ROSA E IAC-2. I- EFEITOS SOBRE OS PARÂMETROS DE PRODUÇÃO ***
}

\author{
J.C. DURIGAN*, R. VICTORIA FILHO**, T. MATUO* \& R.A. PITELLI* \\ * Prof es sor As si sten te-Dout or da FCAV - \\ UNESP, 14.870 - Jaboticabal, SP. \\ ** Professor Adjunto da ESALQ-USP, Caixa \\ Postal, 9 - 13.400 - Piracicaba, SP. \\ *** Parte da Tese de Doutoramento do primeiro \\ autor.
}

\section{RESUMO}

Visando estudar a influência do período de competição das plantas daninhas sobre alguns parâmetros de produçạ̃o da cultura da soja, foram instalados experimentos de campo com os cultivares Santa Rosa e IAC-2 em dois tipos de solos, Latossol Roxo e Latossol Vermelho Escuro - fase arenosa, no município de Jaboticabal, Estado de São Paulo, Brasil.

O delineamento experimental utilizado foi o de blocos ao acaso, sendo os cultivares mantidos sem e com competição das plantas daninhas por períodos cujas exten sões foram 0,10 , $20,30,40,50$ e 60 dias após a emergência.

Com base nos resultados obtidos, pode-se concluir que: o período mínimo do início do ciclo que deve ser mantido livre de competição é de 30 a 40 dias após a emergência para o cultivar Santa Rosa e de 50 dias para o 'IAC-2'; para os dois cultivares, a produção de grãos foi efetivamente aumentada após o $200^{\circ}$ dia sem competição no solo Latossol Roxo e $300^{\circ}$ dia no solo Latossol Vermelho Escuro - fase arenosa, ating indo um valor máximo no $50 .^{\circ}$ dia para o 'S ant a Rosa' e ao redor do $600^{\circ}$ dia para o 'IAC-2'; no ano agrícola de 1977/78 (solo Latossol Roxo), a competição durante os primeiros 20 dias após a emergência causou perdas de produção em ambos os cultivares, entretan to, no de 1978/79 (solo Lat os sol Vermelho Es curo - fase arenosa) este período foi de 40 dias, mostrando a importância das interferências edafo climáticas e das diferentes espécies daninhas, no processo de compet ição; e, dentre todos os parâmetros relacionados à produção de grãos ,o número de vagens por plantả foi 0 mais afetado pela competição das plantas daninhas.

Palavras chave: Períodos de competição, plantas daninhas, soja, produção de grãos.

\section{SUMMARY}

WEED COMPETITION PERIODS IN THE SOYBEAN [Glycine max (L.) Merril] CROP, SANTA ROSA AND IAC-2 CULTIVARS. I-EFFECTS ON THE YIELD PARAMETERS.

The effects of different weed competition periods on some soybean yield parameters were studied in field trials with cultivars Santa Ro-sa and IAC-2 in two soils, "Latossol Roxo" and "Dark-Red Latossol — sandy phase", at Jaboti cabal, São Paulo State, Brazil.

The experimental design of randomized blocks was used. The cultivars were kept with and without weed competition since the emergence for periods of $0,10,20,30,40,50$ and 60 days.

Based on the results the following conclusions may be drawn: the soybean crop should be kept free of weed competition during the first 30 to 40 days for cv. Santa Rosa and during the first 50 days for $\mathrm{cV}$. IAC-2; for both cultivars yield increase was evident beyond first 20 days weeded in "Latossol Roxo" and 30 days for "Dark-Red Latossol - sandy phase", reaching the maximum value at 50th for Santa Rosa cultivar and around 60th days for 'IAC-2'; in the 1977/78 season (for "Latossol Roxo") weed competition during the first 20 days after emergence caused yield losses to both cultivars, whereas in the 1978/79 season ("Dark-Red Latossol — sandy phase") this period extended to 40 first days, showing the importance of edafic-climatic interferences and different weed species in the competition process; among all parameters related to the grain yield the number of pods per plant was the most affected by weed competition.

Keywords: Weed competition, competition periods, soybean, grain yield. 


\section{INTRODUÇÃO}

Entre os fatores que interferem na produção normal da cultura da soja estão as plantas daninh as que competem por água, luz, nutrientes e espaço, reduzindo a produtividade e aumentando o custo de produção. Prejudicam ainda nas operações de colheita causando perdas e contaminações, reduzindo a qualidade e depreciando o produto colhido.

No Brasil, as principais plantas daninhas da cultura da soja já foram identificadas por diversos pesquisadores (3, $15,36,43,44,46)$ e são elas : Brachiaria plantaginca (Link) Hitch., Digitaria horizontalis Willd., Eleusine indica (L.) Gaertn., Acanthospermum australe (Loefl.) O. Kuntze, Acanthospermum hispidum DC, Cenchrus echinatus L., Bidens pilosa L., Portulaca oleracea L., Euphorbia heterophylla L., Sida spp., Ipomoea spp., Richardia brasiliensis Gomez, Sonchus oleraceus L., Emilia sonchifolia DC, Galinsoga paviflora Cav., Ageratum conyzoides L. e Amaranthus spp.

Vários fatores relacion ados à cultura e às plantas daninh as têm grande influência na competição, assim como a época e o período em que permanecem juntas, sendo tudo isto alterado pelas condições edáficas, climáticas e tratos culturais (7).

Os cultivares de soja podem variar bastante com relação à sua habilidade competitiva $(8,25,46)$, assim como a pressão competitiva sobre a comunidade infestante está estreitamente relacionada ao espaçamento e densidade de semeadura da cultura $(24,28)$. D a mesma form a a composiçâo específica $(14,20,30)$, a densidade $(31,32,39,42)$ e a distribuição $(26,41,47)$ das plantas daninhas, são importantes na determinação do grau de competição.

No que se refere ao tempo em que as espécies infestantes competem pelos fatores de crescimento com as plantas cultiv adas, Kasasian e Seeyave (21), em um trabalho de revisâo, sugerem que o período inicial de competição mais importante engloba os primeiros 25 a $33 \%$ do ciclo vegetativo das culturas, cujas partes aéreas permitam uma boa cobertura do solo.

Os estudos, de modo geral, visam a determinação do período, a partir da semeadura ou da emergência da cultura, no qual esta deve permanecer livre da pres ença das plantas daninhas, a fim de que sua produção não seja alterada negativa e significativamente, além de preve nir a competição em fases reprodutivas posteriores desta cultura. É chamado de período total de competição e, na práti ca, é o período que deve ser abrangido pela ação residual de um herbicida de pré emergência. Sua extensão depende da manifestação de inúmeros fatores, justificando os diferentes resultados encontrados na literatura. Ainda, um se gundo tipo do período estudado é aquele, a partir da semeadura ou da germinação, que a cultura pode conviver com o mato, antes que sua produção seja alterada significativamente. Ỏ final deste período, teoricamente, seria a época ideal para a aplicação de um herbicida de pós-emergência ; no entanto, este período não é muito consider ado pois tal época depende mais do estági o de susceptibilidade das plantas daninhas por ocasião da aplicação do produto.

Nos EUA, para diferentes regiões e espécie daninhas, o perí odo inicial livre de competição é bastan te variável, como já foi mostrado por diversos pesquisadores $(2,14,23,50)$. A manutenção de quatro semanas iniciais no limpo foram suficientes para não ocorrer perdas de produção, devido a presença de Ambrosia artemisufolia L., segundo Coble et alii (10).

Para Abutilon theophrasti Medic. e Datura stramonium L. este período é ain da um pouco menor, ou seja, 21 a 23 dias após a semeadura $(17,18)$.

Para as cond ições bras ilei ras, os dados publicados em relação a determinação da duração do período de competição são poucos, Blanco et al (5) estud aram a competição das plantas daninhas, predomin antem ente gramíneas, com o culti var Pelicano e concluíram que não houve diferença significativa na produtividade 
entre parcelas conservadas limpas por 45 a 50 dias após a emergência e aquelas livres de mato durante todo o ciclo. Posteriormente, Blanco et al (6) det erminaram que uma comunidade natural de mato constituída de sete espécies dicotiledôneas, na densidade de 112 plantas $/ \mathrm{m} 2$, somente pass ou a comp etir com a cultura depois dos primeiros 30 dias, sen do que o período crítico de competição se situava entre o $30 .^{\circ}$ e o $45 .^{\circ}$ dia a contar da emergência da soja.

Vários parâmetros de produção da cultura são diretamente afetados pela competição imposta pelas plantas Bani; nhas, tais como, o número de vagens por planta $(13,14,27,29,36,37,38)$, o peso de 100 grãos e número de grãos por vagem $(1,14,39)$, além da produçã̃o final de grãos $(8,11)$.

Por isso, o controle das plantas daninhas é essencial para o desenvolvimento da soja e pode, ser feito através de diversos métodos. É de fundamental importância o conhecimento do período apropriado para a realização desse controle, ou seja, o períod o no qual a presença de plantas daninhas acarretará, fatalmente, prejuízos posteriores.

Desta forma, procurou-se estudar quais as plantas daninhas de maior ocorrência e o período de maior competição, com redução quanti tativa na pro dução dos cultivares de soja Santa Rosa e IAC-2, em dois tipos de solos.

\section{MATERIAIS EM MÉTODOS}

Os experimentos foram instalados e conduzidos nas áreas experimentais pertencentes à Faculdade de Ciências Agrárias e Veteri nárias da UNESP Campus de Jaboticabal, SP, Brasil. Os dois tipos de solos foram classificados como Latossol Rox o e Latoss ol Vermelho Escuro fase arenosa pela Comissão de Solos (12), nos quais os experimentos foram conduzid os nos anos agrícolas de 1977/78 e 1978/79, respectivamente. As características químicas e físicas de ambos, estão no quadro 1.

Quadro 1 - Características químicas e físicas dos solos Latossol Roxo (L.R.) e Latossol Vermelho Escuro fase-arenosa (L.V.E.-fa). Jaboticabal, 1977/78 e 1978/79.

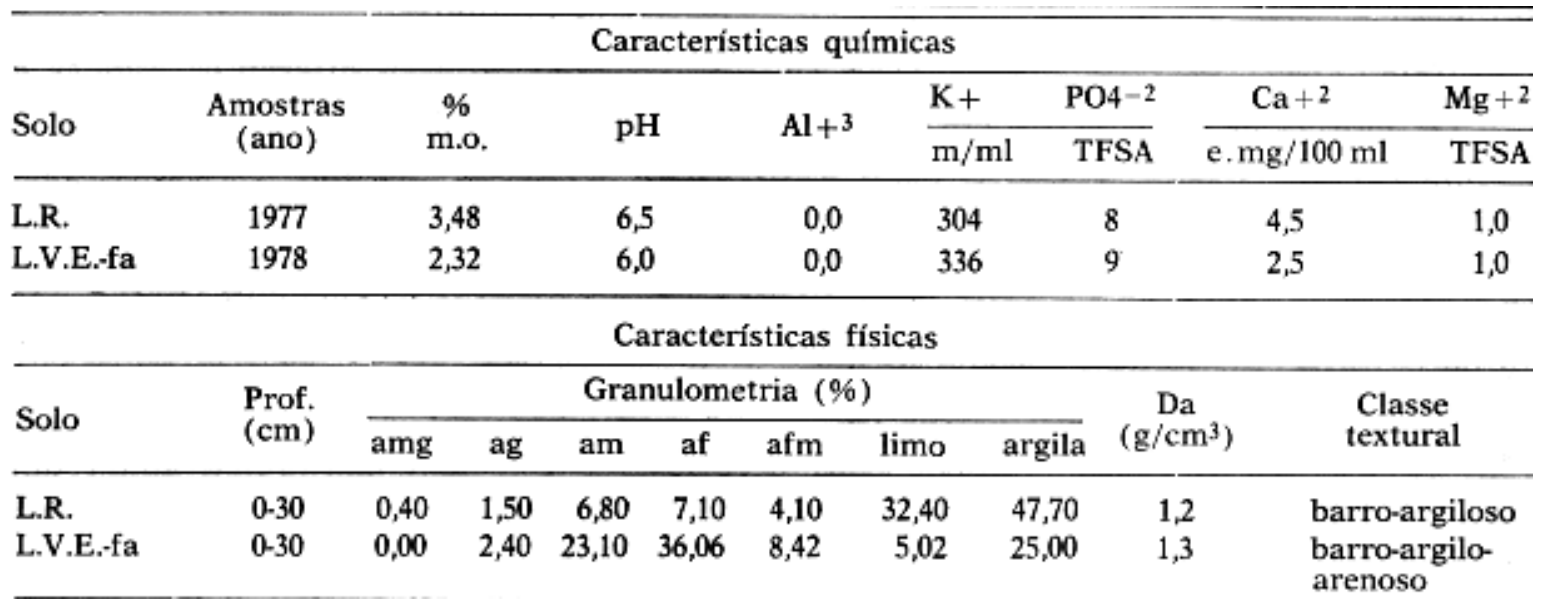

O delineamento experimental adotado para cada experimento foi o de blocos ao acaso, com quin ze tratamentos e quatro repet ições. As parcelas cons titu iram se de cinco linhas com cinco metros de comprimento, espaçadas de 0,6 m. A área total de cada parcela foi de $15 \mathrm{~m}^{2}$, sendo consideradas como área útil as três linhas centrais de quatro metros de comprimento perfazendo, portanto 7,2 $\mathrm{m} 2$. Foram consideradas como bordaduras as duas linhas externas da parcela e as ex- 
tremidades $(0,5 \mathrm{~m})$ de cada uma das linhas centrais.

Elegeram-se dois grupos de tratamentos. No primeiro, a cultura permaneceu livre da competição das plantas daninhas desde a emergência até diferentes períodos do seu ciclo de desenvolvimento, a saber : $0,10,20,30,40,50$ e 60 dias. Após estes períodos, as plantas daninhas que emergissem eram deixadas crescer livremente. No segundo grupo de tratamentos, ocorreu o contrário : a cultura permaneceu em competição com a comunidade infestante desde a emergência, até diferentes períodos do seu ciclo de desenvolvimento 0, 10, 20, 30, 40, 50 e 60 dias. Após estes períodos removiam-se as plantas daninhas presentes na área da parcela e impedia-se o desenvolvime nto de outras, até a colheita. Além dos tratamentos normais anteriormente descrito $s$ foi introduzido um tratame nto, no qual as parcelas não tinham a cultura, permanecendo apenas com plantas daninhas, que se desen volve ram livremente durante todo o período em que foi conduzido o experimento.

As semeaduras, juntamente com as adubações, foram realizadas nos dias 15/11/1977 e 20/11/1978, para os experimentos no solo Latossol Roxo e Latossol Vermelho Escuro fase-arenosa, respectivamente. Os tratamentos propostos começaram a vi gorar qu an do $75 \%$ das plantas de soja já haviam emergido.

Procedeu-se o des dobramento dos graus de liberdade dos tratamentos, comparando-se inicialmente os trat amentos que tiveram um período inicial no limpo com aqueles que tiveram um período inicial no mato. Para facilidade em expres sar o contraste, utilizou-se nas tabelas a notação "L contra M".

Outro contraste foi realizado entre todos os tratamentos que tiveram um períod o inicial no limpo. A notação usada foi "Dentro L". Um terceiro contraste foi elaborado para comparar as parcelas com um período inicial no mato e a no tação utilizada foi "Dentro M". Final- mente, o último contraste cons is ti u na in te ração en tre o si stema in ic ial mantido, no limpo ou no mato, e os dias a partir da emergência, com notação "Sist x D".

Nos tratamentos em que a cultura permanecia um período inicial no mato, a cada dez dias, para os tratamentos respectivos, determinou-se a densidade de plantas daninhas (plantas/m2). A áre a total amostrada por parcela foi de um metro quadrado, atra vés do lançamen to, por duas vezes, de um retângulo metálico com dimensões de 0,5 x $1,0 \mathrm{~m}$. A densidade aos 90 dias, por sua vez, foi determinada nas parcelas do tratamento em que a cultura permaneceu infestada durante todo o ciclo. Para os estágios de 30, 60 e 90 dias após a emergência, além das densidades, foram determinadas as porcentagens das diversas espécies infestantes. O peso da matéria seca das plan tas daninhas foi determinado na época da colheita, nos tratamentos em que as parcelas for am mantidas limpas desde zero até 60 dias após a emergência ; neste caso colheram-se as plantas daninhas em uma área de $0,5 \mathrm{~m}^{2}$.

As colheitas foram realizad as $145 \mathrm{e}$ 148 dias após a semeadura, para os cultivares Santa Rosa e IAC-2, respectivamente, no ano agríc ola de $1977 / 78$ e aos 148 e 152 dias após a semeadura no ano agrícola de 1978/79. Na época da colhei ta, além da produção de grãos por ha, várias outras avaliações foram feitas. Do total de plantas da áre a útil da parcela, dez foram separadas ao acaso para as determinações do número de vagens por planta. $\mathrm{O}$ número de sementes por vagem foi obtido de 100 vagens tomadas ao acaso, do total das produzidas na áre a útil. $\mathrm{O}$ peso de 100 grãos foi determinado tomando-se 500 grãos do total produzido na área útil das parcelas e dividindo-se em cinco lotes.

\section{RESULTADOS E DISCUSSÃO}

A densidade média geral das plantas dan inhas na área experimental, até 90 dias após a emergência dos cultivares de 
soja, foi de 77,4 plantas $/ \mathrm{m}^{2}$, com uma variação máxima de 74,9 a 83,1 plantas/ $\mathrm{m} 2$ entre todos os ensaios realizados nos dois anos agrícolas. Pode-se observar que a densidade média foi bastante homogênea em cada período após a emer gência em que foi avaliada e como se tratavam de infestações naturais, pode-se deduzir que houve uma certa uniformidade em relação ao número de plantas daninhas por área. Estes resultados mos tram que as plantas daninhas emergiram, em sua grande maioria praticamente juntas com a cultura, com poucas oscilações posterio res no seu número. Em uma cultura de amendoim, Bahn et al (4) verificaram que $75 \%$ dos componentes de uma comunidade infestante emergem durante os primeiros 30 dias.

As den sidades médias obs ervadas aos 90 dias após a emergência em todos os ensaios, variando de 68 a 73 plantas/ $\mathrm{m} 2$, foram menores que a observada por Blanco et al (6), que foi de 112 plantas/m2 quan do estudaram a comp eti ção da soja com espécies daninhas dicotiledôneas.

Várias densidades de diferentes espécies daninhas já foram testadas nesta cultura e sempre mostraram efeitos prejudiciais à produção na medida em que são incrementadas, apesar de haver uma estreita dependência do período de competição, justamente o que se pretendeu estudar no presente trabalho $(13,16,17$, $18,39,40)$.

Apesar de não terem ocorrido diferenças signific ativas quan to ao número de plantas daninhas por unidade de área, observa-se que as espécies daninhas foram diferentes entre os dois tipos de solos, como mostram os quadros 2 e 3.

Quadro 2 - Densidade média e porcentagem das espécies infestantes da área experimental, em três épocas $(30,60$ e 90 dias após a emergência) do ciclo da cultura. Levantamentos realizados nos tratamentos em que a cultura sofre u competição nos respectivos períodos (avaliação de 30 e 60 dias) e durante o ciclo todo (avaliação de 90 dias), nos ensaios com cultivares Santa Rosa e IAC-2, em solo Latossol Roxo. Jaboticabal, 1977/78..

\begin{tabular}{|c|c|c|c|c|c|c|c|c|c|c|c|c|}
\hline \multirow{4}{*}{$\begin{array}{l}\text { Espécies daninhas } \\
\text { (Nomes comuns) }\end{array}$} & \multicolumn{12}{|c|}{ Dias após a emergência } \\
\hline & \multicolumn{4}{|c|}{30} & \multicolumn{4}{|c|}{60} & \multicolumn{4}{|c|}{90} \\
\hline & \multicolumn{2}{|c|}{ Santa Rosa } & \multicolumn{2}{|c|}{ IAC-2 } & \multicolumn{2}{|c|}{ Santa Rosa } & \multicolumn{2}{|c|}{ IAC-2 } & \multicolumn{2}{|c|}{ Santa Rosa } & \multicolumn{2}{|c|}{ IAC-2 } \\
\hline & $\mathrm{N} . / \mathrm{m}^{2}$ & $\%$ & $\mathrm{~N} . / \mathrm{m}^{2}$ & $\%$ & $\mathrm{~N} . / \mathrm{m}^{2}$ & $\%$ & $\mathrm{~N} . / \mathrm{m}^{2}$ & $\%$ & $\mathrm{~N} \cdot / \mathrm{m}^{2}$ & $\%$ & $\mathrm{~N} \cdot \% / \mathrm{m}^{2}$ & $\%$ \\
\hline anileira & 20 & 23,5 & 25 & 30,1 & 40 & 43,9 & 32 & 38,1 & 28 & 38,4 & 22 & 32,4 \\
\hline apaga-fogo & 18 & 21,2 & 20 & 24,1 & 20 & 22,0 & 22 & 26,2 & 12 & 16,4 & 18 & 26,5 \\
\hline carr.-de-carneiro & 12 & 14,1 & 10 & 12,0 & 7 & 7,7 & 6 & 7,1 & 8 & 11,0 & 7 & 10,3 \\
\hline mimosa & 14 & 16,5 & 10 & 12,0 & 7 & 7,7 & 8 & 9,5 & 6 & 8,2 & 7 & 10,3 \\
\hline beldroega & 13 & 15,3 & 10 & 12,0 & 6 & 6,6 & 2 & 2,4 & 10 & 13,7 & 6 & 8,8 \\
\hline cap.-marmelada & 5 & 5,9 & 5 & 6,0 & 6 & 6,6 & 10 & 11,9 & 5 & 6,8 & 6 & 8,8 \\
\hline cap--carrapicho & 3 & 3,5 & 3 & 3,6 & 5 & 5,5 & 4 & 4,8 & 4 & 5,5 & 2 & 2,9 \\
\hline Total & 85 & & 83 & & 91 & & 84 & & 73 & & 68 & \\
\hline Monocotiledôneas & 8 & 9,4 & 8 & 9,6 & 11 & 12,1 & 14 & 16,7 & 9 & 12,3 & 8 & 11,8 \\
\hline Dicotiledôneas & 77 & 90,6 & 75 & 90,4 & 80 & 87,9 & 70 & 83,3 & 64 & 87,7 & 60 & 88,2 \\
\hline
\end{tabular}

No solo Latossol Roxo houve uma predominância de dicotiledôneas nas três épocas $(30,60$ e 90 dias após a emergência) de avaliação, como mostra o qua- dro 2. Verificou-se uma relação de cinco até dez dicotiledôneas para cada monocotiledônea presente. A anileira (Indigofera hirsuta L.) e o apaga-fogo (Alternanthera 
Quadro 3 - Densidade média e porcentagem das espécies infestantes da área experimental, em três épocas $(30,60$ e 90 dias após a emergência) do ciclo da cultura. Levantame ntos reali zados nos tratamentos em que a cultura sofre u competição nos respectivos períodos (avaliação de 30 e 60 dias) e durante o ciclo todo (avaliação de 90 dias), nos ens aios com cultivares Santa Rosa e IAC-2, em solo Latossol Vermelho Escuro - fase arenosa. Jaboticabal, 1978/79.

\begin{tabular}{|c|c|c|c|c|c|c|c|c|c|c|c|c|}
\hline \multirow{4}{*}{$\begin{array}{l}\text { Espécies daninhas } \\
\text { (Nomes comuns) }\end{array}$} & \multicolumn{12}{|c|}{ Dias após a emergência } \\
\hline & \multicolumn{4}{|c|}{30} & \multicolumn{4}{|c|}{60} & \multicolumn{4}{|c|}{90} \\
\hline & \multicolumn{2}{|c|}{ Santa Rosa } & \multicolumn{2}{|c|}{ IAC-2 } & \multicolumn{2}{|c|}{ Santa Rosa } & \multicolumn{2}{|c|}{ IAC- 2} & \multicolumn{2}{|c|}{ Santa Rosa } & \multicolumn{2}{|c|}{ IAC-2 } \\
\hline & $\mathrm{N} \cdot \% \mathrm{~m}^{2}$ & $\%$ & $\mathrm{~N} . / \mathrm{m}^{2}$ & $\%$ & $\mathrm{~N} . \% \mathrm{~m}^{2}$ & $\%$ & $\mathrm{~N} . \% / \mathrm{m}^{2}$ & $\%$ & $\mathrm{~N} . / \mathrm{m}^{2}$ & $\%$ & $\mathrm{~N} . \% / \mathrm{m}^{2}$ & $\%$ \\
\hline anileira & 15 & 21,1 & 17 & 20,2 & 15 & 18,7 & 11 & 14,7 & 9 & 12,9 & 10 & 13,7 \\
\hline guanxuma & 10 & 14,1 & 12 & 14,3 & 15 & 18,7 & 18 & 24,0 & 13 & 18,6 & 10 & 13,7 \\
\hline caruru & 7 & 9,9 & 10 & 11,9 & 5 & 6,2 & 5 & 6,7 & 4 & 5,7 & 8 & 11,0 \\
\hline poaia-branca & 3 & 4,2 & 5 & 6,0 & 5 & 6,2 & 6 & 8,0 & 8 & 11,4 & 13 & 17,8 \\
\hline cap.-carrapicho & 16 & 22,5 & 15 & 17,9 & 18 & 22,5 & 15 & 20,0 & 12 & 17,1 & 10 & 13,7 \\
\hline zap.-pé-de-galinha & 7 & 9,9 & 7 & 8,3 & 9 & 11,2 & 8 & 10,7 & 8 & 11,4 & 5 & 6,8 \\
\hline zap.-colchăo & 10 & 14,1 & 12 & 14,3 & 9 & 10,0 & 10 & 13,3 & 8 & 11,4 & 7 & 9,6 \\
\hline zap.-marmelada & 3 & 4,2 & 6 & 7,1 & 5 & 6,2 & 2 & 2,7 & 8 & 11,4 & 10 & 13,7 \\
\hline Total & 71 & & 84 & & 80 & & 75 & & 70 & & 73 & \\
\hline Monocotiledôneas & 36 & 50,7 & 40 & 47,6 & 40 & 50,0 & 35 & 46,7 & 36 & 51,4 & 32 & 43,8 \\
\hline Dicotiledôneas & 35 & 49,3 & 44 & 52,4 & 40 & 50,0 & 40 & 53,3 & 34 & 48,6 & 41 & 56,2 \\
\hline
\end{tabular}

ficoidea (L.) R._Br.) representaram cerca de 50 a $77 \%$ das dicotiledôneas nas três avaliações.

No solo Latossol Vermelho Escuro fase-arenosa a representação de mono e dicotiledôneas estava praticamente dividida em partes iguais, com aproximadamente $50 \%$ de infestação para cada classe (quadro 3).

As espécies daninhas identificadas nas áreas experimentais estão incluídas entre as principais infestantes da cultura da soja e já foram citadas em diversos trabalhos realizados anteriormente sobre o assunto, nas mais diferentes condições ecológicas do Brasil e do mundo $(6,9,19,36)$.

Pelo quadro 4 , pode-se observar que a eliminação das plantas daninhas por diferentes períodos no início do ciclo levou à decréscimos substanciais na matéria seca acumulada delas na época da colheita da soja. A figura 1 ilustra tal fato, evidenciando ainda de forma clara a presença de fortes componentes linea- res nas curvas, ratificados pelos valores de $\mathrm{F}$ iguais a $735,85^{* *}\left(\mathrm{r}^{2}-98,5 \%\right.$ e de $\mathrm{F}$ iguais a $735,85 * *\left(\mathrm{r}^{2}=98,5 \%\right)$ e $579,00 * *$ $\left(\mathrm{r}^{2}=98,9 \%\right)$ para os locais onde se desenvolveram os cultivares Santa Rosa e IAC-2, respectivamente, no solo Latossol Roxo. O mesmo ocorreu no solo Latossol Vermelho Escuro fase-arenosa. Vários trabalhos já mostraram es ta estreita relação entre o período inicial livre das plantas daninhas e a queda no peso da matéria seca dela, avaliado na época da colheita $(8,14$, $29)$. Desta forma pode-se compreender que as plantas daninhas que emergem simultaneamente com a soja são as mais competitivas e trazem as maiores perdas, evidenciando, portanto, que o desenvolvimento das plantas daninhas remanescentes de um bom tratamento herbicida, é bastante diminuído.

Nos quadros 5 e 6 , encontram-se os dados referentes à produção de grãos e número de vagens por planta, respectivamente, para ambos os solos e cultivares estudados. Comparando-se os resultados 
Quadro 4 - Peso da matéria seca das plantas daninhas na época da colheita, nos tratamentos em que as parcelas foram mantidas limpas por 0, 10, 20, 30, 40, 50 e 60 dias após a emergência. O tratamento sem cultura foi mantido apenas com plantas daninhas, até a colheita. Nos dois tipos de solos estudados e nos do is cultivares. Jaboticabal, 1977/7 8 e 1978/79.

\begin{tabular}{|c|c|c|c|c|}
\hline \multirow{3}{*}{$\begin{array}{c}\text { Dias no limpo } \\
\text { após a } \\
\text { emergência }\end{array}$} & \multicolumn{4}{|c|}{ Peso da matéria seca das plantas daninhas $\left(\mathrm{g} / \mathrm{m}^{2}\right)$ (a) } \\
\hline & \multicolumn{2}{|c|}{ L. Roxo } & \multicolumn{2}{|c|}{ L.V.E. - fase arenosa } \\
\hline & Santa Rosa & IAC-2 & IAC-2 & Santa Rosa \\
\hline 0 & $322,0 \quad$ b & $270,0 \quad b$ & 630,0 a & $653,0 \mathrm{a}$ \\
\hline 10 & 290,5 b & 203,5 c & 522,5 b & 602,5 a \\
\hline 20 & $197,8 \quad \mathrm{c}$ & $170,3 \quad \mathrm{c}$ & $401,4 \quad c$ & 550,7 a \\
\hline 30 & $176,7 \quad \mathrm{c}$ & 97,0 & 205,0 & 390,5 b \\
\hline 40 & 55,2 & 81,0 & 102,7 & $203,0 \quad$ c \\
\hline 50 & 46,9 & 36,0 & 46,2 & 90,5 \\
\hline 60 & 8,5 d & 2,3 & 5,7 & $9,0 \quad \mathrm{~d}$ \\
\hline sem cultura & 405,5 a & 323,6 a & 675,4 a & 643,0 a \\
\hline $\mathbf{F}$ & $110,41^{* *}$ & $145,02^{\star \star *}$ & $199,16^{* *}$ & $121,73^{* *}$ \\
\hline C.V. (\%) & 14,62 & 12,74 & 11,75 & 12,01 \\
\hline D.M.S. & 65,23 & 44,76 & 90,33 & 112,02 \\
\hline Regr. 1. grau & $735,85^{* *}(98,5)$ (b) & $579,90^{* *}(98,9)$ & $1026,83^{* *}(96,6)$ & $1288,65^{* *}(97,3)$ \\
\hline Regr. 2." grau & $3,47 \mathrm{NS}$ & $6,19^{ \pm}(100,0)$ & $25,11^{\star \star \star}(98,9)$ & $10,36^{* *}(98,1)$ \\
\hline Regr. 3. grau & $7,36 * *(99,5)$ & $0,21 \mathrm{NS}$ & $11,15^{\star \star}(100,0)$ & $25,64^{\star *}(100,0)$ \\
\hline Desvio & $1,58 \mathrm{NS}$ & $0,46 \mathrm{NS}$ & $0,44 \mathrm{NS}$ & $0,46 \mathrm{NS}$ \\
\hline
\end{tabular}

(a) Números, da mesma colu na, se guidos da mesma letra, não diferem en tre si pe lo teste de Tukey a $5 \%$ de probabilidade.

(b) Coeficiente de determinação (R2).

dos dois quadros pode-se verificar claramente a estreita relação exi stente entre o número de vagens por planta de soja e a produção de grã os por unidade de área. Neste aspecto parece haver unanimidade entre os mais diferentes pesquisadores, pois o número de vagens tem si do, se mp re, um dos parâ me tros de produção mais alterados pela competição $(13,17,18,29,33)$.

Nos experimentos em questão, houve correlações lineares negativas e altamente significtivas entre a matéria seca produzida pelas plantas daninhas na colheita e produção de grãos de soja, com $\mathrm{r}^{2} \mathrm{r} 2=$ $90,2^{\circ} \%$ o e $\mathrm{r}^{2}=98,0 \%$, para os cultivares Santa Rosa e IAC-2, respectivamente, no ano agrícola de 1977/78. 0 mesmo ocorreu no ano agrícola de 1978/79 $\left(\mathrm{r}^{2}=\right.$ $88,4 \%$ para Santa Rosa e $\mathrm{r}^{2} 86,5^{\circ} \%$ para IAC-2 ), no solo Latossol Vermelho Escuro fase-arenosa. A produção de um grama de matéria seca das plantas daninhas por $\mathrm{m}^{2}$ de solo no ano de $1977 / 78$ levou à perdas de 7,79 e 10,81 kg/ha de grãos, nos cultivares Santa Rosa e IAC-2, respectivamente. No ano agrícola de $1978 / 70$, as perdas de produção foram menos pronunciadas, ou seja, de 3,01 e $3,05 \mathrm{~kg} / \mathrm{ha}$, respectivamente. As maiores perdas para os dois cultivares, verificadas no primeiro ano agrícola, provavelmente também foram influenciadas pela baixa precipitação (apenas 7,7 mm em 23 dias) que houve durante $o$ período de florescimento, o qual nos dois anos se iniciou aos 68 dias após a semeadura e é crucial para a produção de soja.

O período mínimo do inicio do ciclo que deve ser mantido no limpo para que não se incorra em perdas estatisticamente significativas de produção e de número de vagens/planta, no cultivar Santa 


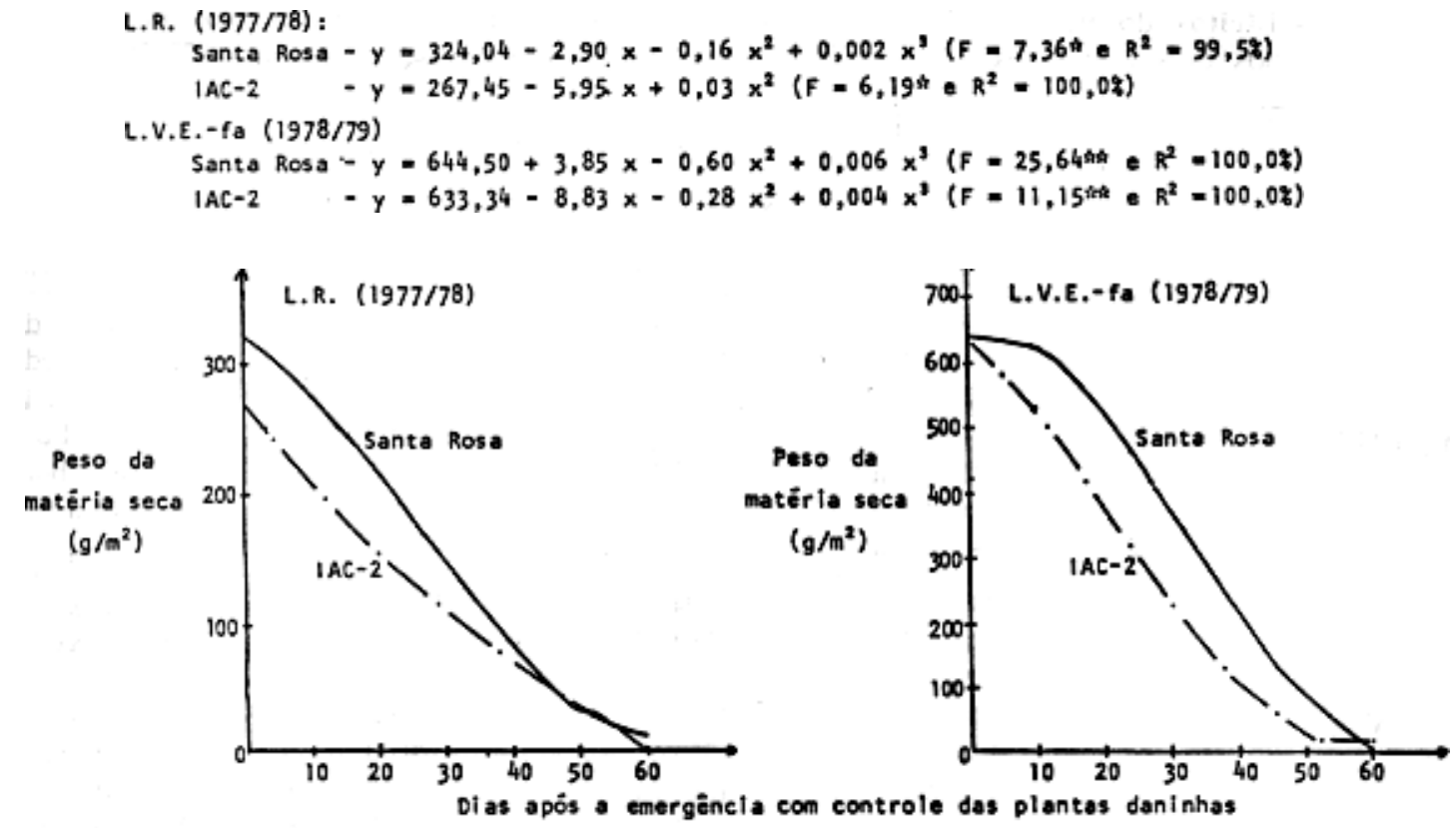

Figura 1 - Representações gráficas das equações de regressão polinomial estimadas com os dados de matéria seca $\left(\mathrm{g} / \mathrm{cm}^{2}\right)$ das plantas daninhas na época da colheita da soja, nos tratamentos com diferentes períodos de controle no início do ciclo. Nos do is tipos de solos e nos dois cultivares. Jaboticabal, 1977/78 e 1978/79.

Rosa est entre 30 a 40 dias após a emergência, nos dois tipos de solos. No entanto, para o 'IAC-2' ele foi um pouco mais dilatado, ou seja, de 50 dias.

A competição por determinados períodos no início do ciclo, mostrou resultados bastante interessantes de produção de grãos, pois os dois cultivares de soja se portaram de forma idntica em relaçã̃o à sensibilidade pela competição em cada tipo de solo, porém tais efeitos variaram entre os solos (quadro 5). Uma das explicações para o fato poderia estar ligada às diferenças entre as espécies daninhas presentes, em cada uma das áreas. Ë certo que as espécies da comunidade infestante interferem de maneiras diferentes, de acordo com a habilidade competitiva de cada uma delas $(22,34,35)$. No ano agrícola de 1977/78 (Latossol Roxo) a competição por 20 dias após a emergência já levou a perdas estatisticamente significativas a produçâo dos dois cultivares, enquanto que no ano seguinte (Latossol Vermelho Escuro fase-arenosa) foram necessários 40 dias para que isto vie sse a ocorrer, mos tran do a importância das interferências edafo-climáticas $\mathrm{e}$ das diferentes espécies daninhas, no processo de competição.

Outro ponto interessante a ser considerado vem a ser o iní cio de competição variável entre as diferentes espécies dan inhas. Este fato pode fazer com que um cultivar de soja resista por um período maior no início do ciclo, sem perdas significativ as na produção depend endo das espécies que integram a comunidade infestante $(2,6,48,49,51)$.

Todos os autores, no entanto, são unanimes em afirmar que a maior ou menor agres sivi dade competitiva depende da int era ção de muito s fatores, que na mai ori a das vezes não se con se gue isolar, tais como, espé cies e densidad es das plantas daninhas, cultivares de soja, ano agrícola, tipo de solo, espaçame nto da cultura e épocas de seme adura, além de outros. 
Quadro 5 - Efeitos do período de competição das plantas daninhas sobre a produção de grãos, nos dois cultivares e nos dois tipos de solos estudados. Jaboticabal, 1977/78 e 1978/79.

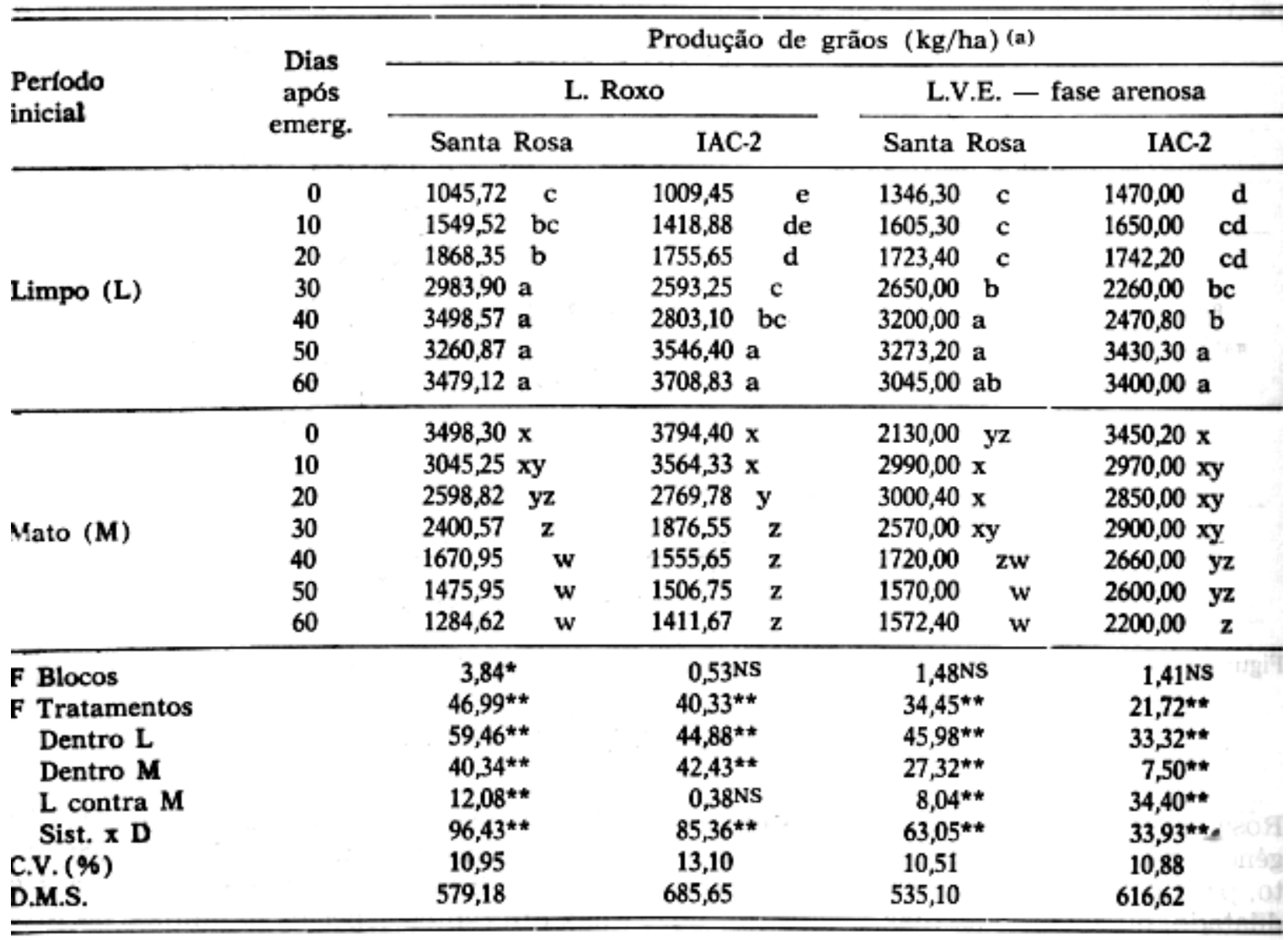

(a) Números, da mesma coluna, seguidos da mesma letra, não diferem entre si pelo teste de Tukey a $5 \%$ de probabilidade.

Os resultados da análise de regressão para produção de grãos e número de vagens por planta, podem ser observados nas figuras 2 e 3 que ilustram as equa ções sobre a produção e núm ero de va gen s por planta, res pec tivamente. Sem pre houve corr elações sign ificativas en tre o aume nto do período inicial no lim po e os acréscimos observados nestes dois parâmetros de produção. Da mesma forma ocorreu entre o aumento do pe ríodo inicial no mato e os dec rés cimos neles. Par a cada dez dias de produção foi de 478,6 kg/ha de grãos ou de 7,1 vagen s por planta, no cultiv ar IAC-2 em solo Latossol Roxo.

Para os dois cultivares, a produção de grãos foi efetivamente aumentada após o $20 .^{\circ}$ dia sem competição no solo Latossol Roxo e $30 .^{\circ}$ dia no solo Latossol Verm elho Escu ro fase -aren osa, atin gindo um valor máximo no $50 .^{\circ}$ dia para o 'Santa Rosa' e ao redor do $60 .^{\circ}$ dia para o 'IAC-2'.

A queda de produção, no ano de 1978 79, para a cultivar IAC-2, esteve linearmente corre lacio nad a com o au mento do período inicial no mato $(\mathrm{F}=$ $28,19 * *$ e $r^{2}=90,8 \%$ ), ou seja, $167,2 \mathrm{~kg} / \mathrm{ha}$ a cada dez dias de competição acrescidos.

Foram avaliados também os efeitos do período inicial, com e sem competição das plantas daninhas, sobre o número 
Quadro 6 - Efeitos do período de competição das plantas daninhas sobre o número de vagens por planta de soja, nos dois cultivares e nos dois tipos de solos es tu da do s. Jabo ca tibal, 1977/78 e 1978/79.

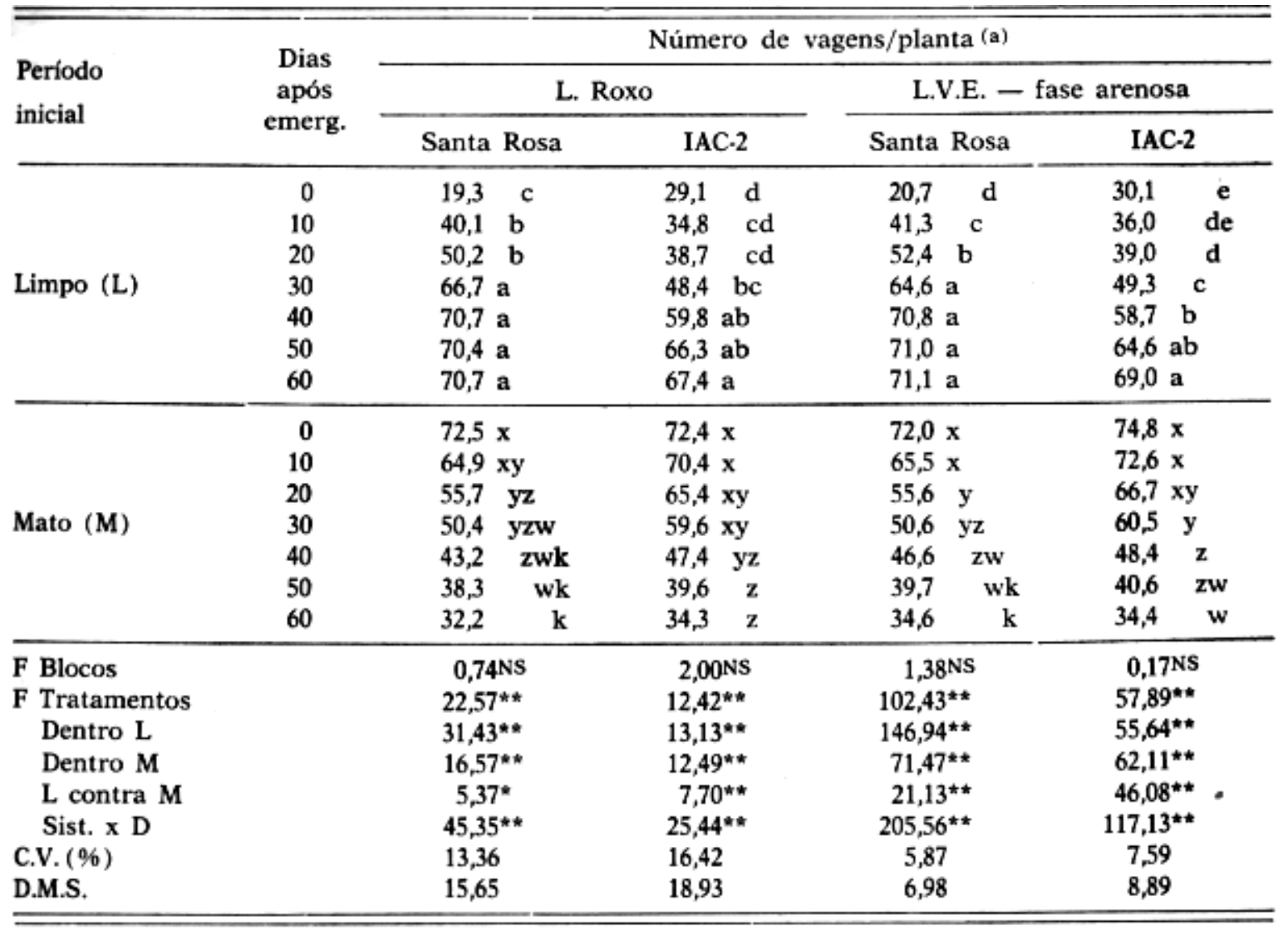

(a) Números, da mesma coluna, seguidos da mesma letra, não diferem entre si pelo teste de Tukey a $5 \%$ de probabilidade.

de grãos por vagem (quadro 7) e peso de 100 grãos (quadro 8).

Como os próprios resultados mostraram, estas duas características genéticas são difíceis de serem alteradas pela competição. Algumas diferenças significativas que ocorreram no solo Latossol Roxo podem ter sido justamente devidas ao efeito somado da competição interespecífica com as deficiências de pluviosidade que ocorreram neste ano agrícola, após o início do florescimento. A validade desta informação é mais uma vez corroborada pela ausência de efeitos sobre estes mesmos parâmetros nos mesmos cultivares, no ano agrícola seguinte
(L.V.E.- fa ), em que não houve este tipo de problema.

Os resultados da análise de regres são esclarecem melhor as tendências de aumento ou diminuição de acordo com as condições impostas às plant as de soja e estas podem ser melhor visualizadas na figura 4.

Para a cultivar IAC-2, houve correlação linear positiva e significativa $\left(\mathrm{F}=44,74 * *\right.$ e $\left.\mathrm{r}^{2}=95,6 \%\right)$ entre o aumento de dias no limpo e o nmero de grãos por vagem, ou seja, cada aumento de dez dias no período inicial livre da competição levou a acréscimos médios 


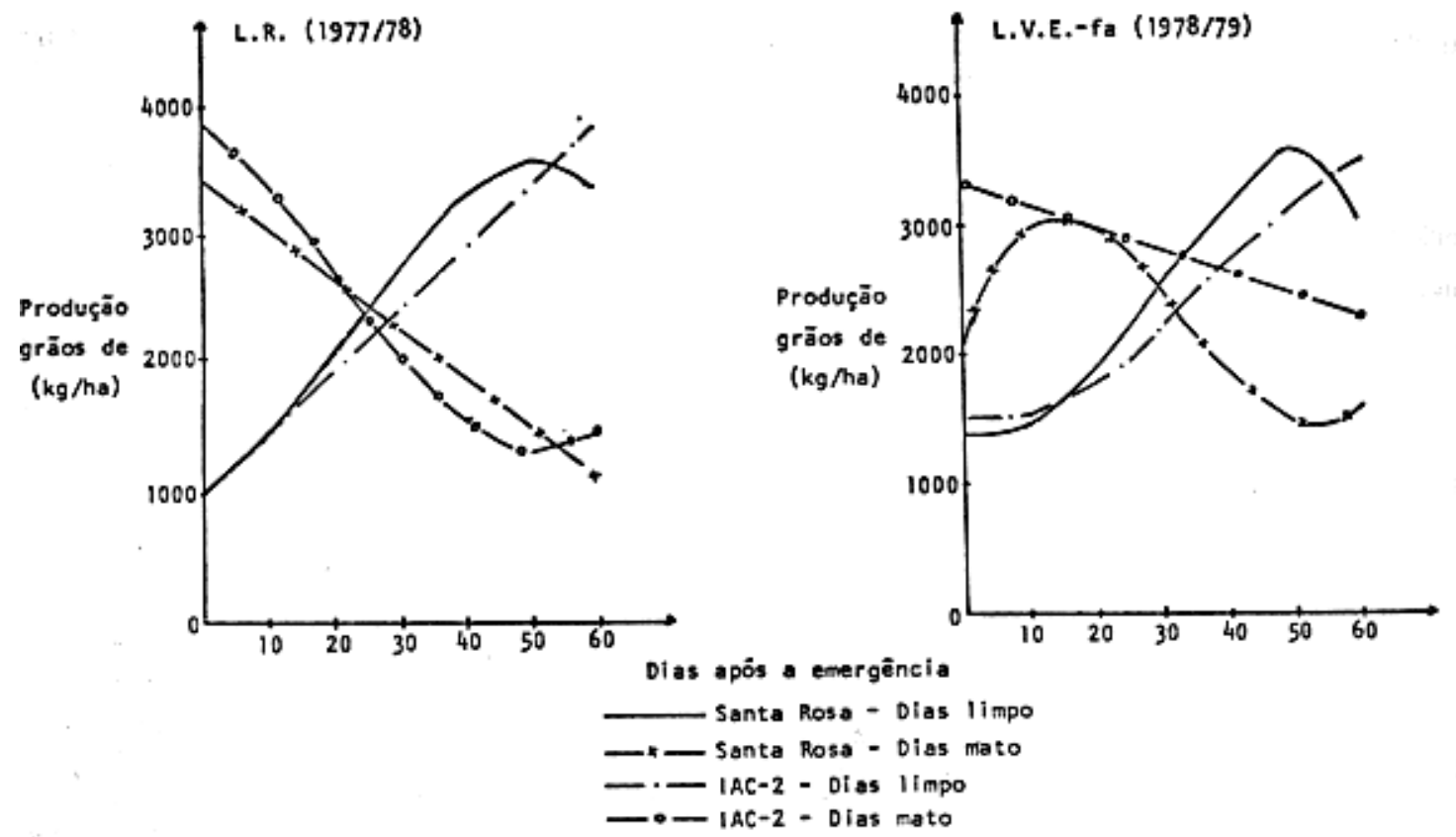

Figura 2 - Representações gráficas das equações de regressão polinomial estimada com os dados de produção de grãos (kg/ha) dos cultivares Santa Rosa e IAC-2, submetidos a diferentes períodos de competição com as plantas daninhas, nos dois tipos de solos estudados. Jaboticabal, $1977 / 78$ e 1978/79.
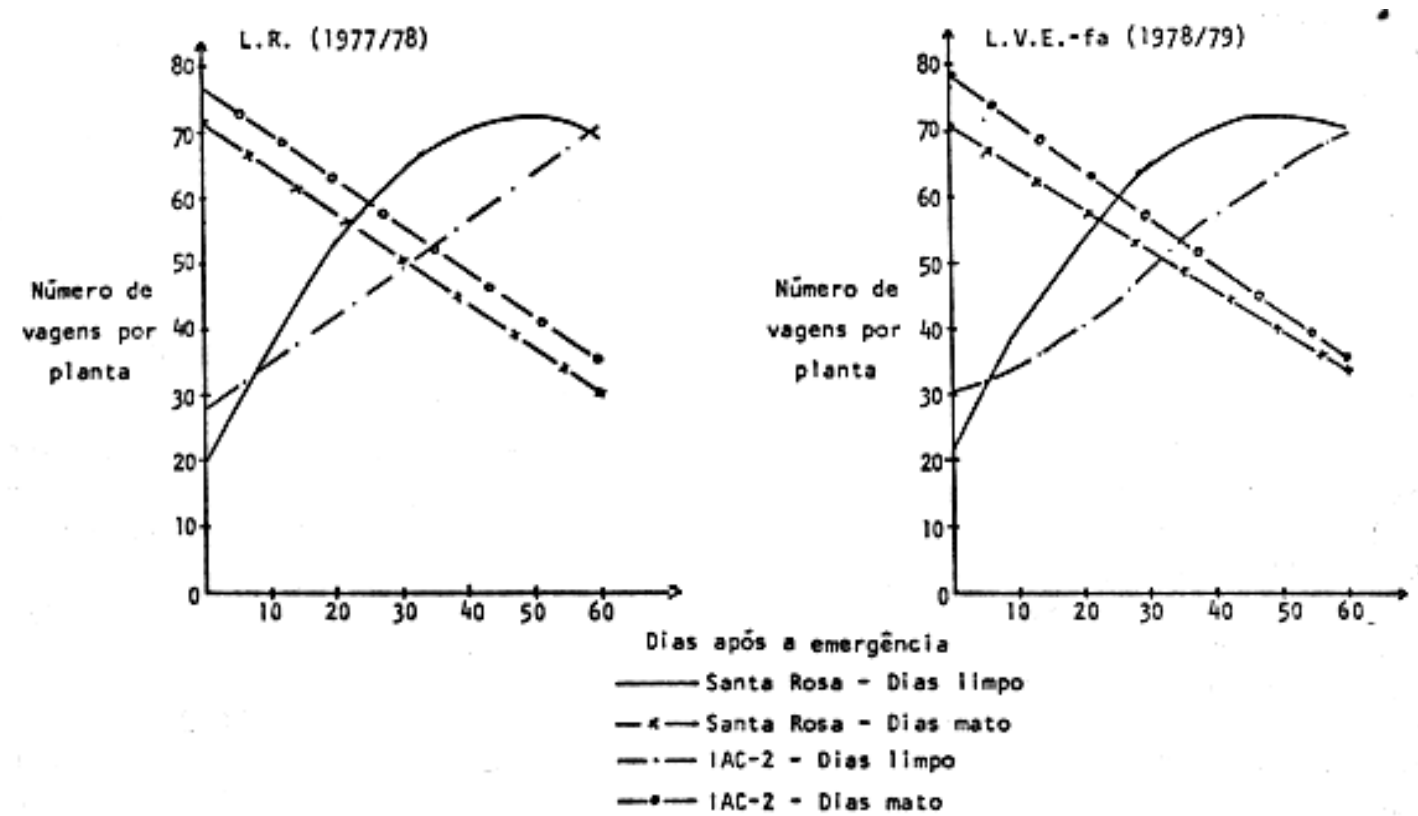

Figura 3 - Representações gráficas das equações de regressão polinomial estimadas com os dados de número de vagens por planta dos cultivares Santa Rosa e IAC-2, submetidos a diferentes períod os de competição com as plantas daninhas, nos dois tipos de solos estudados. Jaboticabal, 1977/78 e 1978/79. 
Quadro 7 - Efeitos do período de competição das plantas daninhas sobre o número de grão por vagem, nos dois cultivares e nos dois tipos de solos estudados. Jaboticabal, 1977/7 e 1978/79.

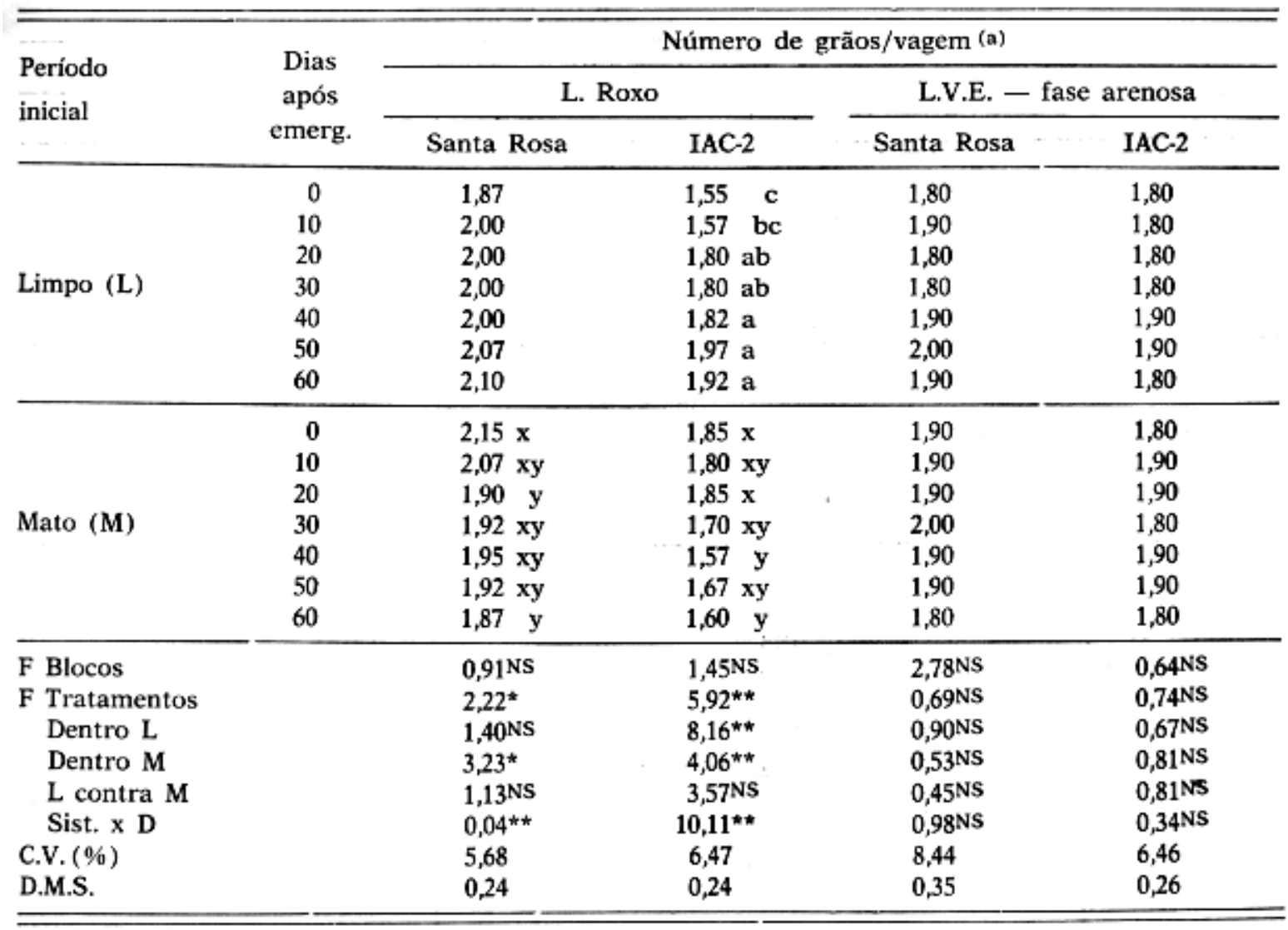

(a) Números, da mesma coluna, seguidos da mesma letra, não diferem entre si pelo teste de Tukey a $5 \%$ de probabilidade.

de 0,07 grão por vage m. Da mesma forma, dez dias a mais no período inicial com competição propor cionaram quedas de 0,05 grão por vagem, evidenciando, portanto, uma correlação linear neg ati va e significativa $\left(\mathrm{F}=15,44 * *\right.$ e $\mathrm{r}^{2}=$ 93,4\%). O cultivar Santa Rosa se portou de maneira semelhante, porém de forma menos sensível aos efeitos dos tratamen tos impostos, com menores queda $(0,04$ grãos/vagem) e aumento ( 0,03 grãos/vagem) em resposta ao acréscimo de dez dias com e sem competição no início do ciclo, respectivamente.

Em relação ao peso de 100 grãos, as tendências também for am as mesmas, não obstante serem ainda menos pronunciadas que para o parâmetro anterior mente mencionado, o que pode ria levar até a serem des prezados tais aumentos ou diminuições, de acordo com o período inicial aumentad o (de dez dias), com ou sem competição.

Desta forma, os períodos iniciais a serem mantidos limpos para que não se incorra em perdas de produção de grãos dos cultivares Santa Rosa (30 a 40 dias) e IAC-2 (50 dias), logicamente também serão suficientes para que não se observem variações mais drásticas nestas características ora discutidas. 
Quadro 8 - Efeitos do período de competição das plantas daninhas sobre o peso de 100 grãos de soja, nos dois cultivares e nos dois tipos de solos estudados. Jaboticabal, 1977/78 e $1978 / 79$.

\begin{tabular}{|c|c|c|c|c|c|}
\hline \multirow{3}{*}{$\begin{array}{l}\text { Período } \\
\text { inicial }\end{array}$} & \multirow{3}{*}{$\begin{array}{c}\text { Dias } \\
\text { após } \\
\text { emerg. }\end{array}$} & \multicolumn{4}{|c|}{ Peso de 100 grãos (g) (a) } \\
\hline & & \multicolumn{2}{|c|}{ L. Roxo } & \multicolumn{2}{|c|}{ L.V.E. - fase arenosa } \\
\hline & & Santa Rosa & IAC-2 & Santa Rosa & IAC-2 \\
\hline Limpo (L) & $\begin{array}{r}0 \\
10 \\
20 \\
30 \\
40 \\
50 \\
60\end{array}$ & $\begin{array}{l}13,50 \mathrm{~b} \\
14,27 \mathrm{ab} \\
14,35 \mathrm{ab} \\
14,45 \mathrm{a} \\
14,07 \mathrm{ab} \\
14,40 \mathrm{ab} \\
14,40 \mathrm{ab}\end{array}$ & $\begin{array}{l}15,10 \\
15,40 \\
15,20 \\
15,30 \\
15,50 \\
15,60 \\
15,70\end{array}$ & $\begin{array}{l}13,70 \\
13,90 \\
14,00 \\
13,70 \\
13,70 \\
13,70 \\
14,10\end{array}$ & $\begin{array}{l}14,10 \\
14,10 \\
14,10 \\
14,60 \\
14,80 \\
14,30 \\
14,30\end{array}$ \\
\hline Mato $(\mathrm{M})$ & $\begin{array}{r}0 \\
10 \\
20 \\
30 \\
40 \\
50 \\
60\end{array}$ & $\begin{array}{l}14,45 \\
14,42 \\
14,17 \\
14,07 \\
13,67 \\
13,95 \\
13,70\end{array}$ & $\begin{array}{l}15,50 \\
15,50 \\
15,40 \\
15,30 \\
15,30 \\
15,40 \\
15,20\end{array}$ & $\begin{array}{l}14,10 \\
14,00 \\
13,80 \\
13,60 \\
13,90 \\
13,80 \\
14,00\end{array}$ & $\begin{array}{l}14,50 \\
14,30 \\
14,60 \\
14,50 \\
14,50 \\
14,50 \\
14,40 \\
\end{array}$ \\
\hline $\begin{array}{l}\text { F Blocos } \\
\text { F Tratamentos } \\
\text { Dentro L } \\
\text { Dentro M } \\
\text { L contra M } \\
\text { Sist. X D } \\
\text { C.V. (\%) } \\
\text { D.M.S. } \\
\end{array}$ & & $\begin{array}{l}1,97 \mathrm{NS} \\
2,32^{\star} \\
2,54^{\star} \\
2,21 \mathrm{NS} \\
1,61 \mathrm{NS} \\
3,39^{\star} \\
2,98 \\
0,93 \\
\end{array}$ & $\begin{array}{l}1,37 \mathrm{NS} \\
0,46 \mathrm{NS} \\
0,79 \mathrm{NS} \\
0,21 \mathrm{NS} \\
0,01 \mathrm{NS} \\
0,76 \mathrm{NS} \\
3,15 \\
1,06 \\
\end{array}$ & $\begin{array}{l}1,01 \mathrm{NS} \\
0,22 \mathrm{NS} \\
0,22 \mathrm{NS} \\
0,25 \mathrm{NS} \\
0,07 \mathrm{NS} \\
0,17 \mathrm{NS} \\
5,27 \\
1,60\end{array}$ & $\begin{array}{l}9,74^{* \star} \\
0,77^{\mathrm{NS}} \\
1,30 \mathrm{NS} \\
0,16 \mathrm{NS} \\
1,23 \mathrm{NS} \\
0,65 \mathrm{NS} \\
3,35 \\
1,06\end{array}$ \\
\hline
\end{tabular}

(a) Números, da mesma coluna, seguidos da mesma letra, não diferem entre si pelo teste de Tukey a $5 \%$ de probabilidade.

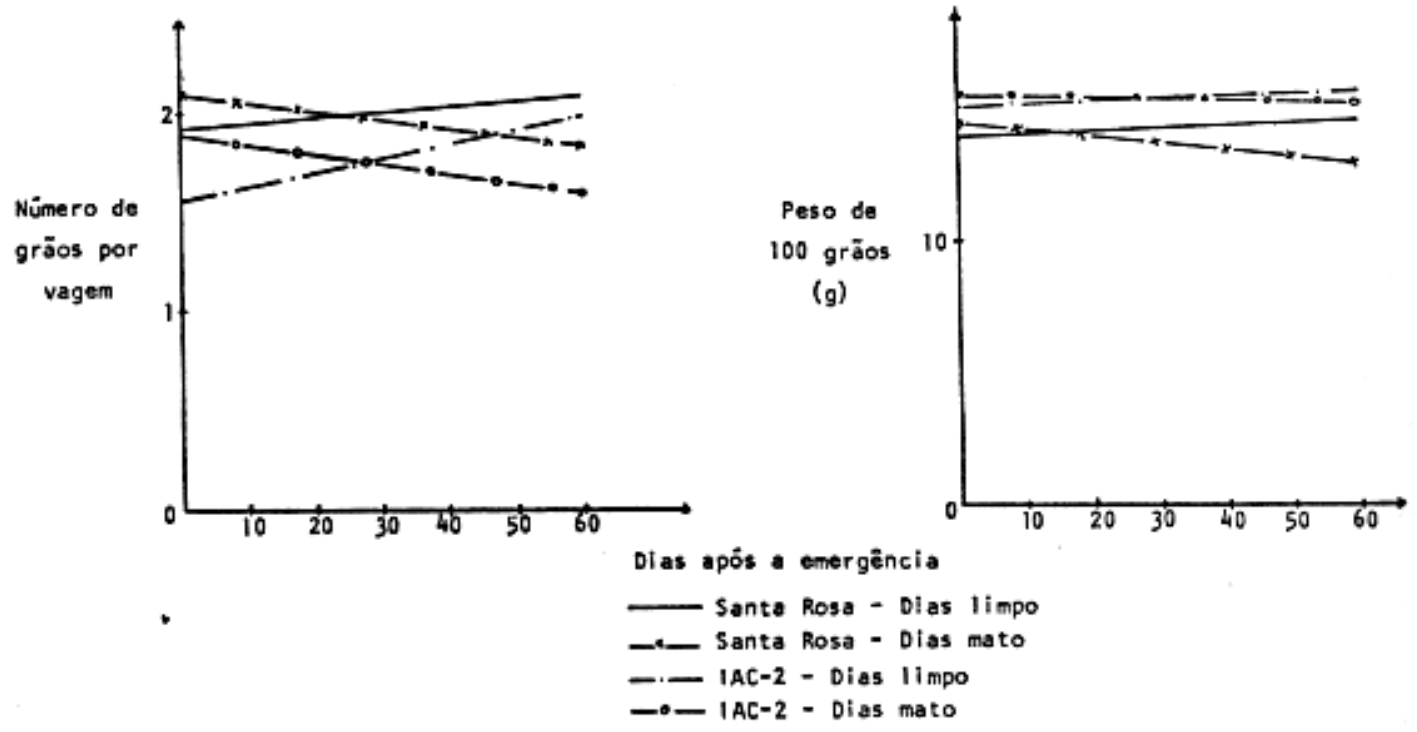

Figura 4 - Representações gráficas das equações de regressão polinomial estimadas com os dados de número de grãos por vagem e peso de 100 grãos (g) dos cultivares Santa Rosa e IAC2, submetidos a diferentes períodos de competição com as plantas daninhas, no solo Latossol Roxo. Jaboticabal, 1977/78. 


\section{LITERATURA GITADA}

1. Adams, M.W. Basis of yield component compensation in crop plantas with special reference ao the fiels bean (Phaseolus vulgaris). Crop. Sci., 7: 505-510, 1967.

2. Barrentine, W.L. Common cocklebur competition in soybeans. Weed Sci., 22 (6): 600-603, 1974.

3. BASF - Divisão Agroquímica. Invasoras na cultura da soja. Vol. 1, 90 pp.

4. Bhan, V.M.; Sinch, M. \& Maurya, R.A. Crop weed competition studies in groundnuts. Indian J. of weed Sci., 3: 32-36, 1971.

5. Blanco, H.G.; Oliveira, D.A.; Araujo, J.B.M. \& Grossi, N. Observaçōes sobre o período em que as plantas daninhas competem com a soja (Glycine max (L.) Merril). $O$ Biológico, 39 (2): 31-35, 1973.

6. Blanco, H.G.; Oliveira, D.A. \& Araujo, J.B.M. Período crítico de competição de uma comunidade natural de mato em soja (Glycine max (L.) Merril). In: Seminário Nac. de Pesq. de Soja, I, Anais, vol. 2, p. 151-157, 1979.

7. Bleasdale, J.K.A. Studies on plant competition. In: Harper, J.L. The Biology of weeds. Oxford, Black weel Sci. Publication, p. 133-142, 1960.

8. Burnside, O.C. Soybean (Glycine max) growth as affected by weed removal, cultivar, and row spacing. Weed Sci., 27 ()5: 562-562, 1979.

9. Cerdeira, A. L.; Roessing, A.C. \& Voll, E. Controle integrado de plantas daninhas me soja. Circular Técnica n. ${ }^{\circ} 04$, CNPSo-EMBRAPA, 48 pp., 1981.

10. Coble, H.D.; Williams, F.M. \& Ritter, R.L. Common Ragweed (Ambrosia artemissufolia) interference in soybeans (Glycine max). Weed Sci., 29 (3): 339-342, 1981.

11. Coble, H.D. \& Ritter, R.L. Pennsylvania smartweed (Polygonum pensylvanicum) interference in soybeans (Glycine max). Weed Sci., 26 (6): 556-559, 1978.

12. Comissão de Solos. Levantamento de reconhceimento dos Solos do Estado de São Paulo e Rio de Janeiro. Rio de Janeiro, CNEPA/SNPA, 639 p. (Boletim 12). 1960.

13. Eaton, B. J.; Feltner, K.C. \& Russ, O.G. Venice mallow competition in soybeans. Weed Sci., 21 (2): 89-94, 1973.

14. Eaton, B.J.; Russ, O.G. \& Feltner, K.C. Com. petition of velvetleaf, Prickly sida, and venice mallow in soybeans. Weed Sci., 24 (2): 224-228, 1976.

15. Forster, R. \& Alves, A. Os herbicidas na lavoura da soja. A Granja, 32: 32-38, 1976.
16. Geddes, R. D.; Scott, H. D. \& Oliver, L. R. Growth and water use by Common cocklebur (Xanthium pensylvanicum) and soybeans (Glycine max) under field conditions. Weed Sci., 27 (2): 206-212, 1979.

17. Hagood Jr., E.S.; Bauman, T.T.; Willians, J. L. \& Schreiber, M.M. Growth analysis of soybeans (Glycine max) in competition with velvetleaf (Abutilon theophrosti). Weed Sci., 28 (6): 729-734, 1980.

18. Hagood Jr., E.S.; Bauman, T.T.; Willians, J. L. \& Schreiber, M.M. Growth analysis of soybeans (Glycine max) in competition with Jimsoweed (Datura stramonium). Weed Sci., 29 (4): 500-504, 1981.

19. Hammerton, J.L. Effects of weed competition, defoliation and time of harvest on soybean. Expl. Agric., 8 (2): 333-338, 1972.

20. Hoveland, C.S.; Buchanan, G.A.; Crowley, R.H.; Teem, D.H. \& McGuire, J.A. Response of weed and crop species to shade. In: Annual Meeting weed Sci. Soc. of America, Alabama, p. 1-2, 1978.

21. Kasasian, L. \& Seeyave, J. Cirtical periods for weed competition. Pans, 15: 208-212, 1969.

22. Knake, E.L. \& Slife, F.W. Competition of Setaria faberii in corn and soybeans. Weeds. 4 (5): 26-29, 1962.

23. Loonis, W.E. Basic studies in botany, ecology and plant physiology. Proc. North Cent. Weed Conf. (s. 1.), 15: 81, 1958.

24. McWhorter, C.G. \& Barrentine, W.L. Cocklebur control in soybeans as affected by cultivars seeding rates, and methods of weed control. Weed Sci, 23 (5): 386-390, 1975.

25. McWhorter, C.G. \& Hartwig, E.E. Competition of Johnsogranss and cocklebur with six soybean varieties. Weed Sci., 20 (1): 56-59, 1972.

26. Michell, R. L. \& Russel, W. J. Root development and rooting patterns of soybean [Glycine $\max$ (L.) Merril] evaluated underfield conditions. Agron. J., 63: 313-316, 1971.

27. Mooloni, M.R.; Knake, E.L. \& Slife, F.W. Competition of smooth pigweed with corn and soybeans. Weeds, 12 (2): 126-128, 1964.

28. Moss, P.A. \& Hartwig, N. L. Competitive control of Chenopodium album in a corn-soybean inter-crop. In: Proceedings of Northastern Weed Sci. Soc., Pennsylvania, p. 21-28, 1980.

29. Murphy, T.R. \& Gossett, B.J. Influence of shading by soybeans (Glycine max) on weed supression. Weed Sci., 29 (5): 610-615, 1981.

30. Noguchi, K.; Nakagawa, K. \& Takabayashi, 
M. Studies on competition between uplond crops and weeds. I-Effects of different cropping systems of the weed community. Japanese J. of crop Sci., 46 (4): 504-509, 1977.

31. Oakes, R.L. Interference and control of two varieties of jimson weed [Datura stramonium L. var. Stramonitum and var. tatula L. Torr.] in soybean [Glycine max (L.) Merril] with oxyfluorfen 2-chloro-1-(3-ethoxy-4-nitrozphenoxy) - 4 - (trifluoromethyl) benzene] and RH 8817 [2-chloro-1-(3-carboxyethyl - 4 - nitrophenoxy)-4-(trifluoromethyl) benzene]. Michigan State University. 132 p. (PhD Thesis), 1980.

32. Oliver, L. R.; Frans, R. E. \& Talbert, R. E. Field competition between Tall Morningglory and soybean. I-Growth analysis. Weed Sci., 24 (5): 482-488, 1976.

33. Orwick, P.L. \& Schreiber, M.M. Interference of red-root Pigweed (Amaranthus retro. flexus) and Robust Foxtail (Setaria viriris var, robustaalba or var. robusta pur. purea) in soybeans (Glycine max). Weed Sci., 27 (6): 665-674, 1979.

34. Pavlychenko, T.K. \& Harrington, J.B. Competitive efficiency of weeds and cereal crops. Can. J. Res., 10: 77.94, 1934.

35. Pitelli, R.A. Efeitos do período de competição das plantas daninhas sobre a produtividade do amendoim (Arachis hypogaea L.) e o teor de macronutrientes em suas sementes. ESALQ-USP, Piracicaba (SP), 90 p. (Dissertação de Mestrado), 1980.

36. Pitelli, R.A. \& Neves, A.S. Efeitos da competição das plantas daninhas sobre algumas características morfológicas e agronômicas de plantas de soja. In: Seminário Brasileiro Herb. Ervas Daninhas. 12., Fortaleza (CE). Resumos, p. 104, 1978.

37. Pyon, J.Y. Effect of weed-free maintenance periid on the growth and yield of soybeans. J. of the Korean Soc. of Crop Sci., 23 (2): 150-153, 1978.

38. Pyon, J. Y. \& Kim, Y. R. Competitiveness effects of annual nuds on soybeans. I-Effects of weed competitions time on the growth and yield of soybeans. J. of the Korean Soc. of Crop. Sci., 23 (1): 86-89, 1978.

39. Rathman, D. P. \& Miller, S. D. Wild oat (Avena fatua) competition in soybean
(Glycine max). Weed Sci., 29 (4): 410-414, 1981.

40. Schultz, M.E. \& Burnside, O.C. Distribution, competition, and phenology of Hemp dogbane (Apocynum cannabi) in Nebras. ka. Weed Sci., 27 (5): 565-570, 1979.

41. Scott, H.D. \& Oliver, L.R. Field competition between tall morningglory and soybean. II-Development and distribution of root systems. Weed Sci., 24 (5): 454-460, 1976.

42. Scott, H.D.; Griffis, C.L.; Brewer, D.W. \& Oliver, L.R. Simulation of plant competition. Transaction of the ASAE, 21 (5): 813-817, 1978.

43. Sichmann, W; Lasca, D.H.C.; Labate, N.; Assis, A.F.F.; Bertini, K. \& Salvio Neto, J. Produção de soja. Campinas, Ed. CATI, p. $15-16,1973$.

44. Silva, H.T.; Weiss, B.; Koehn, D.; Arzivenco, L. \& Dutra, P.R. Plantas invasoras da cultura da soja (Glycine max (L.) Merril) no Rio Grande do Sul. In: Seminário Brasileiro de Herbicidas e Ervas Daninhas, $100^{\circ}$ Santa Maria (RS), Resumos, p. 41, 1974.

45. Soares, A.A. Estudo preliminar da distribuiçẩo geográfica e por cultura das principais plantas daninhas do Estado de São Paulo. FCTV-UNESP Campus de Jaboticabal, 35 p. (Trabalho de Graduação), 1976.

46. Staniforth, D.W. Responses of soybean varieties to weed competition. Agron. J., 54: 11-13, 1962.

47. Teare, I.D.; Kanemasu, E.T.; Powers, W.L. \& Jacobs, H.S. Water-use efficiency and its relation to corp canopy area, stomatal resistance and distribution. Agron. J. 65: 207-211, 1973.

48. Thurlow, D.L. \& Buchanan, G.A. Competition of sicklepod with soybeans. Weed Sci., 20 (4): 379-384, 1972.

49. Weber, C.R. \& Staniforth, D.W. Competitive relation ship in variable weed and soybean stands. Agron. J., 49: 440-444, 1957.

50. Wheatley, L.E. \& Cole, R.H. Weed competition in soybean. Proc. 21th Neast Weed Control Conf., p. 567-574, 1967.

51. Wilson, H.L. \& Cole, R.H. Morniglgory competition in soybeans. Weeds, 14: 49-51, 1966. 